\title{
Use of Foreign Films in Cultivating Intercultural Communicative Competence in ELT-A Case Study*
}

\author{
Jianying Yue \\ North China Electric Power University, Beijing, China
}

\begin{abstract}
Foreign films have long been used in English Language Teaching (ELT) and been proved effective in improving learners' linguistic competence. Cultivating Intercultural Communicative Competence (ICC) has gradually become a vital goal in English Language Teaching (ELT). However, whether foreign films can be used to improve learners' ICC is less researched. Taking Byram's ICC model, this paper tends to show foreign films can also be effective in improving learners' ICC. This article reports an empirical study designed to explore the processes students engage in when viewing Disney film Mulan in a Chinese college classroom. Students' study blogs, quizzes, and interviews are major research data and the analysis of the data illustrated foreign films' role in cultivating learners' ICC and explored the mental process of students' interpretation of foreign films.
\end{abstract}

Index Terms - foreign films, English Language Teaching (ELT), Intercultural Communicative Competence (ICC), Mulan

\section{INTRODUCTION}

The goal of English Language Teaching (ELT) has changed from a focus on linguistic competence to the current wider emphasis on intercultural communicative competence (ICC) with the fast pace of globalization. However, due to limited intercultural communication experiences in classrooms, students are confined to what they learned in the textbook and lack of real intercultural communication encounters. Foreign films, with their authentic language, real physical settings and human interactions, can be used as scenario simulation by teachers and learners. With appropriate task designs, foreign films can also be used in the classroom to get learners acquainted with foreign social and cultural life, thus bridging the gap for lack of real intercultural communication encounters.

Actually, foreign films have long been used in ELT classrooms and have been instrumental in improving learners' listening, speaking and reading skills (Stempleski and Tomalin 2001; Bouman 1996; Chapple and Curtis 2000). However, most of them are concerned with the improvement of learners' linguistic competence. They can be also used in teaching cultures (Kramsch, 1995; Roell, 2010). There is less emphasis on their use in developing intercultural communicative competence. This paper tends to explore the use of foreign films in developing learners' ICC. It also reports on students' own interpretation of foreign films, which has so far attracted little attention. Another issue is how students come to understand another culture through watching films.

Among a number of ICC models, the one proposed by Byram $(1997,2009)$ is adopted as a guideline for this study. Byram's model incorporates knowledge, attitudes, skills of interpreting/relating, skills of discovery/interaction, and critical cultural awareness. This study tends to take Byram's model as the framework and explores how students interpret foreign films and how the interpretation processes improve students' intercultural communicative competence.

\section{USE OF FOREIGN FILMS IN ELT}

Foreign films are the most well-known non-print media used in ELT. They are easily accessed and readily available in most countries around the world. Besides their popular means of entertainment, their use as teaching material is also significant amongst language teachers. (Sabouri \& Zohrabi, 2015). At the very beginning, films were used as aids to help learners comprehend literature in the language being learnt (Bouman, L.1996). Films then were used to help improve learners' English proficiency including grammar (Ruhl, B. 1978) speaking and listening skills (Chapple, L. and A. Curtis, 2000), vocabulary, reading, translation (Mollica 1978) and writing skills (Kasper,2000).

Kramsch (1995) makes the point that intercultural content in film can reveal how people from different backgrounds think and interact by focusing on areas such as immigration, racism and discrimination, etc.. Consequently, using film has the potential to not only raise greater awareness of cultural differences (and similarities) but also serves to generate a feeling of empathy in learners. Roell (2010) suggests that films can be used successfully in various ways within

\footnotetext{
${ }^{*}$ This paper is supported by China Scholarship Council (CSC)
} 
education and ELT in order to help learners develop language skills; interpersonal communication skills and intercultural awareness. Elissa Tognozzi (2010) made a qualitative study to analyze how short clips from foreign language films could be incorporated into the teaching of language and culture in the university classroom.

Foreign films show learners a certain culture both from general and specific viewpoints, such as daily life and lifestyle practices. Sherman (2003) believes that authentic film is a 'window on English language culture.' So, foreign films cannot only be used for teaching but also for educating students about social aspects and they have great potential in facilitating language and culture classroom especially in terms of fostering ICC.

\section{BYRAM’s MODEl OF INTERCULTURAL COMMUNICATION COMPETENCE (ICC)}

Byram (1997) proposed a model of ICC and was widely accepted in foreign language teaching and Intercultural Communication studies. His model includes five elements: attitude, knowledge, skills of interpreting and relating, skills of discovery and interaction, and critical awareness.

The first component, attitude, refers to the student's "curiosity and openness, readiness to suspend belief about other cultures and belief about one's own" (as cited in Elola \& Oskoz, 2008). This factor is about the willingness to delay unbelief about other cultures and belief about one's own. Students are not supposed to base a judgement on their own cultures.

The second factor, knowledge, refers to familiarity with "social groups and their products and practices in one's own country and in the country of one's interlocutor, and knowledge of the general processes of societal and individual interaction" (Byram, 1997). Idoia Elola \& Ana Oskoz (2008) suggests that much of this knowledge is relational. That is, how the inhabitants of a country perceive another country. This knowledge is also social, which means how individual acquire knowledge regarding their own social group and the social group of others. Part of the knowledge of the intercultural speaker is being aware that one's "natural" way of interaction with others is a product of socialization, and that other cultures have parallel but different modes of interaction (Elola \& Oskoz, 2008).

Actually it is impossible for the learners to acquire all the necessary knowledge needed in various cultural contexts. Therefore, it is imperative for the learners to have skills that enable them to understand unfamiliar knowledge and relate the knowledge to their familiar knowledge.

Firstly, learners need to have skills of interpreting and relating, which refers to the "ability to interpret a document or event from another culture, to explain it and relate it to the documents from one's own (Byram, 1997).

Secondly, learners need to have skills of discovery and interaction, which refers to the "ability to acquire new knowledge of a culture and cultural practices and the ability to operate knowledge, attitudes and skills under the constraints of real-time communication and interaction (Byram, 1997). Learners should be able to explore new culture and develop the ability to integrate their knowledge, attitudes and skills even at the disadvantage of the absence of real-time communication.

Sometimes learners may be tortured by the conflict of their own sets of values and the newly acquired ones, even though they are quite open-minded, tolerant of others' beliefs and values. A learner's own values may affect their responses toward those of the target culture in a positive or negative manner. It then becomes necessary to make learners aware of their own behaviors and beliefs by developing a critical cultural awareness; that is, by developing the "ability to evaluate critically and on the basis of explicit criteria, perspectives, practices and products in one's own and other cultures and countries (as cited in Elola \& Oskoz, 2008). With critical awareness, the learners are expected to adopt a more open-minded attitude towards another cultural value while maintaining their own sets of values.

\section{Method AND Data Analysis}

The research was carried out in Beijing, China. Research participants were non-English major Chinese undergraduate students. They must pass the College English Test Band 4 (CET 4) first then they are qualified for this elective course. CET 4 certificate holders are more likely to have a good command of English so that teaching effectiveness will be greatly enhanced.

The Disney film Mulan was selected as the teaching material. The plot of the film is based on a Chinese folktale, but it is different from the commonly shared Chinses version. The main actress Mulan is a tomboyish girl who dressed like a man, behaved like a man. Once she was frustrated at the fact that she was out of tune with the traditional feminine virtues and she failed to live up to the expectations of traditional gender roles in China. However, she happened to go to fight the war against the Huns in her father's place. Only in the military; a male world; Mulan could find the real self and live her own life. Finally, Mulan won the war, saved the Chinese kingdom, and lived happily ever after.

Disney Mulan was chosen because it is a well-known tale among Chinese people. The film version of the story provides teaching materials which are both educating and fun. It also provides opportunities for reflection.

However, researchers often challenged the distorted representations of Chinese culture in the film. The discrepancy between western version and eastern version is a good example of developing students' sense of cultural differences and intrigue critical thinking. This material could be used to inspire critical classroom discussions regarding the plurality and fluidity of culture as well as those pertaining to Chinese heritage and cultural authenticity.

The study takes Byram's ICC model as the framework, and students are required to write about the film's plot, their 
understanding of the film, and compare Disney version of Mulan with its Chinese counterpart. Semi-structured interviews in five periods were conducted with the students. 30 students took part in the research and among them 10 were selected randomly for the interviews.

TABLE 1.

DATA SOURCES

\begin{tabular}{lll}
\hline Contents & Collection Period (5 weeks) & Data \\
\hline \hline Attitude & First week & Students' Study Blogs \\
\hline Knowledge & Second week & Quiz \\
\hline Skills of Interpreting and Relating & Third week & Students' Study Blogs and Interviews \\
\hline Skills of Discovery and Interaction & Fourth week & Students' Scripts \\
\hline Critical Evaluation & Fifth week & Students' Study Blogs and Interviews \\
\hline
\end{tabular}

\section{FINDINGS}

\section{Attitude}

Students were asked to write in their blogs about the reason why they choose this selective course and their attitude towards the role of films in developing their language proficiency as well as ICC. The reasons for choosing the course vary, eg. interests, learn about other cultures, prepare themselves to study abroad etc. but mostly falls on these two categories: instrumental and integrative. It shows that most students understand how important culture is and they are open to other cultures and quite curious about different cultures.

When talking about the role of films in the class, they show strong desire to watch films, since they are both educating and entertaining. Students like to incorporate film watching into their class because of its authenticity of language and scenes, its diversity of content and form, its vivid reflection of social culture, customs, values and ways of thinking. The result agrees with Mark Pegrum, Linda Hartley and Veronique Wechtler (2005) research. They reported on and analyzed the results of a survey of attitudes towards foreign films among UK university students of French, German and Spanish. The findings reveal students' limited exposure to and relative lack of familiarity with non-anglophone cinema; yet this coupled with considerable enthusiasm for the greater integration of film into language courses (Mark Pegrum, Linda Hartley and Veronique Wechtler 2005).

\section{Knowledge}

After watching the Disney film Mulan, students took part in a quiz about the plot of the film in order to check whether they have understood the content. The ten quiz questions center on the narrative elements of when, where, who, what and why questions. 23 students get 100 percent right, and 5 students get 90 percent right, and 2 students get 80 percent right. It shows that despite the language barrier, most students can get the main plot of the film. Comprehending the plot is basic to any deeper understanding of themes and characters. The interviews revealed the methods students took to facilitate their understanding among which watching with English soundtrack and Chinese subtitles proved to be the most common ways students adopted. The length of sentences, the speed of the dialogue appeared to be the main obstacles to understanding.

\section{Skills of interpreting and relating}

At this stage, students are asked to retell the Disney Mulan story in their own words and are encouraged to identifying differences by comparing the characters with their Chinese counterparts. LJM wrote this in his blog:

Disney version of Mulan is more like an American girl, who values individualism more than anything else. She is unwilling to cater to the traditional female models, instead she longs for freedom. While in Chinese version of Mulan, the emphasis is on her filial piety to her father, which is a high value in Chinese culture.

Data of this kind show that students are stimulated to compare characters in both cultures. They are able to interpret a literature from another culture, and relate it to the literatures from their own.

Some students go into details of the film to interpret the culture reflected in the film. DZX wrote about the song Reflection in the film:

"Look at me, I will never pass for a perfect bride or a perfect daughter. Can it be I'm not meant to play this part?" by defining the social role for women as a "part" that one has to play, the song fortifies the irreconcilable relationship between individual selfhood and the Chinese tradition.

HLT commented on Disney Mulan's humor, she writes:

Disney Mulan is more like a funny cartoon character than a brave female hero in Chinese history. However, I think it is acceptable for this change, for it has to cater to the needs of U.S. audience.

\section{Skills of discovery and interaction}

To practice this skill, students are asked to recontextualize the story, that is, think about or reflect on the story in a different context. Some students make the recontextualizing by putting themselves into Mulan's shoes. In the interview, LM said:

If I were Mulan, I would like to marry a man who can shoulder the responsibility of serving the military for the family and I took care of the family at home. Anyway, battlefield is male domain.

A male student comments on Disney Mulan's portrait of Mulan as a representation of gender oppression. He wrote 
that in his blog:

I think Mulan is a victim of the traditional Chinese culture, and her struggle is against Chinese traditional gender roles. Male Chinese characters are the incarnation of the abusive Chinese culture. However if I were living at that time, I will not fall in love with a girl like Mulan for her existence makes me feel impotent.

\section{Critical awareness}

Some students show strong critical awareness commenting on Disney Mulan. LLY thinks that "the royal dragon symbol is embodiment of Chinese ancestor, who is supposed to be solemn, respectful. While the dragon is ridiculed into a frivolous lizard." WMX, criticized Disney Mulan for its deviation from the original Chinese version. He wrote:

The Chinese Mulan was decontextualized and displaced with only some superficial Chinese culture elements such as the Great Wall, the Forbidden City, dragons, ancestor worship and martial arts.

NWY complained that Chinese people complexion was not as dark as the Disney's portrait, and the figure of Mulan is kind of plump, which did not fit in with Chinese ideals of beauty.

In the interview, LM said: It is ridiculous to see the ancestors of Mulan dance with rock music. We Chinese people honor and respect our ancestors, and it looks silly for them to dance like this!"

\section{DISCUSSION}

Belinda Y. Louie (2006) reported a similar project carried out in a U.S. school. The teacher assigned her fourth-grade students five different versions of Mulan: The Song of Mulan (Lee, 1995), The Ballad of Mulan (Zhang, 1998), The legend of Mulan (Jiang, 1992), Fa Mulan (San Souci, 1998), and Disney's Mulan video (Coats et al., 1998). The researcher collected various types of information including videoing taped records of all the instructional sections, field notes, teaching journals, students' journals, and students' projects and students' interviews. The research centered on students' cross cultural understanding from three categories: critical, empathetic and conceptual understanding. Compared with Belinda's data, I found similarities as well as differences in American and Chinese students' understanding of Disney Mulan.

Both students from different cultural background demonstrate skills of interpreting and relating. In Belinda. Y. Louie (2006) study, the teacher asked students to write in their journals about two items: (1) Mulan's feelings and reasons for her decision to fight in the war and (2) whether it be acceptable and honorable for Mulan to go to war without her parents' permission. In her journal Megan wrote,

Mulan probably would have gone without permission because she finally cares for her family, especially her father. Because her father was the weakest and because any small things could hurt him because he's weak and frail. So she probably asked first. But if her parents said she couldn't go, she would probably go anyway because she cares (Belinda. Y. Louie, 2006, P443)

Most U.S. students believed that it was acceptable for Mulan to disobey her parents when she believed that she was doing the right thing (Belinda. Y. Louie 2006).

I asked students to write the same topic. However, most Chinese students thinks it is not acceptable and honorable for Mulan to go to war without her parents' permission. In her Journal WMW wrote,

It is unbelievable for Mulan to join the military without her parents' permission, because in Chinese culture parents' will must be obeyed. Any disagreement with parents will be regarded as serious offence.

Most Chinese students believed that it was unacceptable for Mulan to disobey her parents even if she thought she was doing the right thing.

Both students show skills of discovery and interaction. U.S. students connected with Mulan using dialogue, by imagining how she might have felt or how they might act in her place.

Kim: Mulan's dad was not strong enough. At least in China at that time, they allowed a substitute. But my dad, when he was young, he and some of the kids that he knew had to go to the army, too. (Belinda. Y. Louie, 2006, P445)

As is revealed from Belinda. Y. Louis (2006) study, U.S. students disliked the fact that Mulan had to deceive the government by disguising herself as a man, they realized that the government might not have allowed Mulan to replace her father if she had enrolled as a woman. They found Mulan somewhat strange because she lied to the government. They were unused to questioning a brave and admirable protagonist about negative elements in her life (Belinda. Y. Louie 2006).

I asked students to write about their attitudes towards Mulan's deception. Most students show empathy to Mulan's white lie.

ZL : Mulan had no choice. Even though she lied, it is a white lie.

U.S. Students also showed critical awareness regarding Disney Mulan. They believed the Disney version added many imaginary items to make the story "more enjoyable." They realized that Disney's additions compromised the authenticity and accuracy of the story. Chinese students also criticized Disney's distortion of Chinese culture. However, they both show their preference for the Disney version. U.S. student Don commented that, "although Disney added a lot of fake stuff in the story, they made the story funny." A Chinese student revealed in her interview that she liked the Disney Mulan because "it displayed a funny and different Mulan, who is more attractive."

Both U.S. students and Chinese students showed conceptual understanding of culture. Conceptual understanding is the awareness that culture is a social construct and that there are individual differences with a culture (Matsumoto, 
1996). It also involves the acknowledgement that we look at the world through our cultural filters and we act according to our cultural norms. Students with conceptual understanding of culture begin to accept the range of values and behaviors among different cultural groups (Cotton, 1996). Only a few U.S. students involved in the project demonstrated conceptual understanding at the end of the class. Students discussed their abstract understanding of culture.

James: People think differently.

Jay: People from different cultures may think differently. (Belinda. Y. Louie, 2006, P446)

\section{CONClusion AND RECOMMENDATIONS FOR LANGUAGE TEACHERS}

The research sheds light on the use of films in language and culture teaching. Teachers can recommend foreign films with abundant cultural elements to students and design tasks based on Byram's ICC model with the aim of improving students' ICC. But the selection of film should depend on the focus of the class or on the teaching objectives of a specific module. At the same time, teachers should bear it in mind that films are story telling from a particular director's point of view and therefore reflect a personal perspective. This point of view may or may not be credible to some students, depending on their own interpretations of the film (Mark Mallinger \& Gerard Rossy, 2003). Other limitations may result from individual differences among students themselves. Teachers should be selective with scenes with swear words, pornography or violence that may be offensive to students with strong religious belief or moral values. Appropriate task design is also significant. Byram's ICC model is a good theoretical foundation for the task design. Other theories of ICC are also encouraged to be used in designing tasks with the purpose to increase learners' ICC awareness.

The case study illustrates that foreign films especially those with diverse cultural elements are instrumental in developing students' ICC. The interviews with the students demonstrate that they were active viewers with so much going on in their minds instead of passive viewers. Students showed considerable enthusiasm for the greater integration of foreign films into Intercultural Communication course. Since intercultural communication tasks are more related with participants' intercultural social relationships and entail intercultural communicative acts, the language teacher should involve students into a variety of social roles and speech events via the incorporation of activities, such as role play, simulation, cultural comparison and drama into classroom. The data analysis showed that viewing foreign films and reflecting on students' interpretation of foreign films is helpful to develop learners' ICC.

The case study also has implications for the classroom teaching in relation to selection of appropriate films, the role of the teacher, the design of class activities. In addition to the common approach of seeing the film itself as the teaching material, the study shows that students themselves can be treated as a source of material in that students conduct complex sense-making activities which produce rich and dynamic meanings ( Linda Hui Yang \& Mike Fleming, 2013). By selecting appropriate films, asking appropriate prompt questions, assigning cultural context tasks, teachers can facilitate the development of the students' intercultural communicative competence.

\section{REFERENCES}

[1] Belinda Y. Louie. (2006). Guiding principles for teaching multicultural literature. The Reading Teacher, 59(5), 438-448.

[2] Bouman, L. (1996). Video: an extra dimension to the study of literature. The Language learning Journal, 13, 29-31.

[3] Byram, M. (1997). Teaching and assessing Intercultural Communication Competence. New York: Multilingual Matters.

[4] Byram, M. (2009). The intercultural speaker and the pedagogy of foreign language education. In D.K. Deardorff (Eds.), The Sage Handbook of Intercultural Competence, London: Sage, 321-2.

[5] Chapple, L. and A. Curtis. (2000). Content-based instruction in Hong Kong: students responses to film. System, 28,419-33.

[6] Coasts, P. (Producer), Cook, P., \& Bancroft, T. (Directors). (1998). Mulan. [Motion Picture]. United States: Buena Vista Home Entertainment.

[7] Cotton, C. (1996). A bold experiment in teaching values. Educational Leadership, 53(8), 54-58.

[8] Elissa Togonozzi (2010). Teaching and evaluating language and culture through film. Italica. 87(1), 69- 91.

[9] Idoia Elora \& Ana Oskoz. (2008). Blogging: fostering Intercultural Competence Development in foreign language and study abroad contexts. Foreign Language Annals, 41(3), 454-477.

[10] Jiang, C. (1992). The legend of Mulan. Monterey, CA: Victory Press.

[11] Kasper. L. F. (2000). The imagery of rhetoric: film and academic writing in the discipline-based ESL course. Teaching English in the Two-year College, 28, 52-9.

[12] Kramsch, C. (1995). The cultural component of language teaching. Language Culture and Curriculum, 8(2), 82-92.

[13] Lee, J. (1995). The song of Mulan. Arden, NC: Front Street.

[14] Linda Hui Yang, Mike Fleming. (2013). How Chinese college students make sense of foreign films and TV series: implications for the development of intercultural communicative competence in ELT. The Language learning Journal, 41(3), 297-310.

[15] Mark Mallinger, Gerard Rossy. (2003). Film as a Lens for Teaching Culture: balancing concepts, ambiguity, and paradox. Journal of Management Education, 27 (5), 608-624.

[16] Mark Pegrum, Linda Hartley and Veronique Wechtler. (2005). Contemporary cinema in language learning: from linguistic input to intercultural insight. Language Learning Journal, 32 (1), 55-62.

[17] Matsumoto, D. (1996). Culture and psychology. Pacific Grove, CA: Brooks Cole.

[18] Mollica, A. (1978). The film advertisement: a source for language activities. Canadian Modern Language Review, 34 (2), 221-43. 
[19] Roell, C. (2010). Intercultural training with films. English Teaching Forum, 2, 2-15.

[20] Ruhl, B. (1978). ESL teaching techniques, Volumes 1 and 2. Edmonton, Canada: Alberta Vocational Centre.

[21] Sabouri. H. and Zohrabi, M. (2015). The Impact of watching English subtitled movies in vocabulary learning in different genders of Iranian EFL learners. International Journal of Studies in English Language and Literature, 3(2), 110-115.

[22] San Souci, R. (1998). Fa Mulan: The story of a woman warrior. New York: Hyperion.

[23] Sherman. J. (2003). Using authentic video in the language classroom. Cambridge: Cambridge University Press.

[24] Stempleski, S. and B. Tomalin. B. (2001). Film. Oxford: Oxford University Press.

[25] Zhang, S. (1998). The ballad of Mulan. Union City, CA: Pan Asian Publications.

Jianying Yue was born in Beijing, China in 1979. She received her MA degree in linguistics and applied linguistics from Harbin Institute of Technology in 2003.

She is currently a lecturer in the school of Foreign Languages, North China Electric Power University, Beijing, China. Her research interests include Intercultural Communication and English Language Teaching (ELT).

Ms. Yue is a member of the China Association for Intercultural Communication (CAFIC). 